University of Texas Rio Grande Valley

ScholarWorks @ UTRGV

$11-2020$

\title{
Effects of Employee Personality on the Relationships between Experienced Incivility, Emotional Exhaustion, and Perpetrated Incivility
}

\author{
Jennifer L. Welbourne \\ The University of Texas Rio Grande Valley, jennifer.welbourne@utrgv.edu \\ Gerardo A. Miranda \\ The University of Texas Rio Grande Valley \\ Ashwini Gangadharan
}

Follow this and additional works at: https://scholarworks.utrgv.edu/mgmt_fac

Part of the Business Administration, Management, and Operations Commons, Human Resources Management Commons, and the Management Sciences and Quantitative Methods Commons

\section{Recommended Citation}

Welbourne, J. L., Miranda, G., \& Gangadharan, A. (2020). Effects of employee personality on the relationships between experienced incivility, emotional exhaustion, and perpetrated incivility. International Journal of Stress Management, 27(4), 335-345. https://doi.org/10.1037/str0000160

This Article is brought to you for free and open access by the Robert C. Vackar College of Business \& Entrepreneurship at ScholarWorks @ UTRGV. It has been accepted for inclusion in Management Faculty Publications and Presentations by an authorized administrator of ScholarWorks @ UTRGV. For more information, please contact justin.white@utrgv.edu,william.flores01@utrgv.edu. 
Effects of Employee Personality on the Relationships between Experienced Incivility, Emotional Exhaustion, and Perpetrated Incivility

\author{
Jennifer L. Welbourne ${ }^{1}$, Gerardo Miranda ${ }^{1}$, and Ashwini Gangadharan ${ }^{2}$ \\ ${ }^{1}$ Department of Management, University of Texas- Rio Grande Valley \\ ${ }^{2}$ Department of Management, Kutztown University
}

\begin{abstract}
Author Note
Jennifer L. Welbourne, Department of Management, University of Texas Rio Grande Valley, Jennifer.Welbourne@utrgv.edu; Gerardo Miranda, Department of Management, University of Texas Rio Grande Valley, Gerardo.Miranda01@utrgv.edu; Ashwini Gangadharan, Department of Management, Kutztown University, gangadharan@ kutztown.edu.

This research was funded in part by a University of Texas-Pan American Faculty Research Council Grant. A portion of the results from this study were presented at the annual meeting of the Southern Management Association (SMA). We have no known conflict of interest to disclose.
\end{abstract}

Correspondence regarding this article should be addressed to: Jennifer L. Welbourne, Department of Management, 1201 West University Drive, University of Texas Rio Grande Valley, Edinburg, TX 78539; Email: Jennifer.Welbourne@utrgv.edu 


\begin{abstract}
Workplace incivility refers to low-intensity negative behaviors that violate workplace norms of respect. Incivility is known to be a type of stressor in the workplace, with recent research drawing attention to how it may differentially affect employees with varying personality traits. Drawing from a stressor-strain theoretical framework, we examined the moderating effects of four of the Big Five personality traits (agreeableness, conscientiousness, neuroticism, and extraversion) on the relationship between individuals' experienced incivility and their subsequent emotional exhaustion and perpetrated incivility toward others in the organization. Results from a 2-wave survey of 252 working adults indicate that personality traits moderated the relationship between the stressor of experienced incivility and the examined strains. Agreeableness strengthened the relationship between experienced incivility and the strains examined here. On the other hand, highly conscientious employees were less likely (than employees scoring low on this trait) to perpetrate incivility toward others or become emotionally exhausted in response to experiencing incivility. No moderating effects were found for the personality traits of neuroticism and extraversion. Implications for research and practice are discussed.
\end{abstract} Keywords: Incivility, perpetrated incivility, emotional exhaustion, personality 


\section{Effects of Employee Personality on the Relationships between Experienced Incivility, Emotional Exhaustion, and Perpetrated Incivility}

Due to the high frequency with which people in the workplace experience incivility (Porath \& Pearson, 2013) and the negative outcomes that are associated with it, research on workplace incivility has attracted much attention from both scholars and practitioners. Incivility, defined as low-intensity negative behaviors that are ambiguous in intent and violate workplace norms of respect (Andersson \& Pearson, 1999), can include behaviors such as excluding someone from an important meeting, addressing someone unprofessionally, or showing disregard for a colleague's ideas. Experiencing incivility at work is linked to negative outcomes, such as psychological distress (Cortina, Magley, Williams, \& Langhout, 2001; Tremmel \& Sonnentag, 2018) and exhaustion (Rhee, Hur, \& Kim, 2017; van Jaarsveld, Walker, \& Skarlicki, 2010). Targets of incivility are also more likely to engage in behaviors that are disadvantageous to the organization, such as counterproductive work behavior (Welbourne \& Sariol, 2017) and incivility toward other employees (Gallus, Matthews, Bunk, Barnes-Farrell, \& Magley, 2014). Relationships between incivility and these impacts can be understood through a stressor-strain framework (Spector, 1998; Spector \& Jex, 1998), where incivility is a chronic low-grade interpersonal stressor that evokes negative psychological and behavioral strains in its targets.

Employees may experience occupational stressors, such as incivility, in subjectively different ways, depending on their personality (Bowling \& Jex, 2013). In particular, certain personality traits may strengthen or weaken the relationship between stressors and strains (Spector, Chen, \& O'Connell, 2000). Because incivility is a stressor that is low in intensity and ambiguous in intent, personality may be particularly important in influencing how employees view and respond to this stressor. Indeed, calls for deeper investigation into how personality 
traits relate to individuals' responses to occupational stressors (Bowling \& Jex, 2013) coincide with recent attention to individual differences in models of workplace incivility (Beattie \& Griffin, 2014; Sliter, Withrow, \& Jex, 2015; Taylor \& Kluemper, 2012; Zhou, Yan, Che, \& Meier, 2015). As such, the current study contributes to recent research streams investigating how individual differences influence responses to the stressor of workplace incivility.

While past research has begun to explore the role of personality in determining how targets of incivility respond to this subtle form of workplace deviance, research is still limited in terms of the traits and outcomes that have been examined. Much of the existing literature in this domain has focused on how neuroticism influences targets' responses to incivility (e.g., Beattie \& Griffin, 2014; Zhou et al., 2015), while there is less emphasis on how other traits from the Five Factor Model (FFM) of personality (McCrae \& John, 1992) influence the strains associated with this stressor. Additionally, while past studies have focused on how employees' personality traits influence their perceptions and frequency of experienced incivility (Milam, Spitzmueller, \& Penney, 2009; Sliter \& Jones, 2016; Sliter et al., 2015), there has been less attention to the ways in which personality might mitigate or enhance incivility's impact on employee exhaustion and the further spread of uncivil behavior within the organization. We suggest that attention to these outcomes is important, because they reflect the degree to which incivility influences employees' ability to interact effectively with coworkers and customers in future interactions.

The current study addresses these gaps in the existing literature while seeking to further understand the role of personality in workers' responses to the stressor of workplace incivility. We examine four traits (agreeableness, conscientiousness, extraversion, and neuroticism) within the FFM (McCrae \& John, 1992) that we argue are of particular relevance in understanding how employees interpret and respond to incivility, a workplace stressor uniquely characterized by its 
low intensity, ambiguous intent, interpersonal nature, and disregard for mutual respect (Andersson \& Pearson, 1999). Agreeableness describes individuals who are good-natured, cooperative, and care about others (McCrae and Costa, 1987). As such, highly agreeable individuals may be particularly sensitive to an interpersonal stressor such as incivility which violates their important values of cooperation and harmony. Conscientiousness characterizes individuals who are well-organized, diligent, and achievement oriented (McCrae \& John, 1992). Because conscientious individuals adhere strongly to norms (McCrae \& Costa, 1990) and hold others to high standards (Bowling \& Jex, 2013), they may also be more sensitive to incivility, which violates norms of respect and courtesy. Extraversion is described as being active, assertive, enthusiastic, outgoing, and talkative (Costa \& McCrae, 1992) and may provide interpersonal resources (Bowling \& Jex, 2013) that protect against stressors, such as incivility. Finally, neuroticism is characterized by anxiety, frustration, and nervous tension (McCrae \& Costa, 1987), potentially resulting in greater sensitivity to experienced incivility. Due to the lack of theoretical (Bowling \& Jex, 2013) and empirical (Grant \& Langan-Fox, 2007) support for relating openness to experience to the occupational stressor-strain relationship, we did not examine this final trait of the FFM.

We apply a stressor-strain framework to examine the extent to which these personality traits moderate the effects of experienced incivility on employees' subsequent emotional exhaustion and incivility perpetrated toward others. Emotional exhaustion is a component of burnout that manifests as an inability to show empathy to clients and customers (Shirom, 2010), while perpetrated incivility reflects a failure to treat customers and coworkers with respect (Andersson \& Pearson, 1999). We focus on these strains not only because of their direct impact on employee well-being, but also because of their disruptive influences on employee 
performance (Taris, 2006; Sliter, Sliter, \& Jex, 2012). Responding to incivility with further incivility may also encourage a culture of incivility, culminating in long-term negative consequences for the organization (Pearson, Andersson, \& Porath, 2005).

The current study makes several theoretical and practical contributions. By examining the extent to which personality traits sensitize employees to strains associated with experienced incivility, our research dovetails with recent investigation of individual differences in workplace incivility (Beattie \& Griffin, 2014; Cortina, Kabat-Farr, Magley, \& Nelson, 2017; Sliter \& Jones, 2015; Taylor \& Kluemper, 2012; Zhou et al., 2015) to further clarify the role of personality in the context of incivility. More broadly, our study responds to calls for greater understanding of how personality influences responses to occupational stressors (Bowling \& Jex, 2013).

Additionally, the inclusion of agreeableness, conscientiousness, and extraversion in our model draws attention to personality traits that have been less frequently examined as moderators between incivility and its impacts, or more generally in the relationship between occupational stressors and strains (Bowling \& Jex, 2013). While the trait of neuroticism has typically claimed priority in the study of occupational stressors, other FFM traits are often understudied despite their potential relevance to how employees respond to stressors (Bowling \& Jex, 2013). We argue that in the context of incivility these other FFM traits may be of particular importance. Specifically, with their emphasis on cooperativeness and harmony (agreeableness) and adherence to norms and high standards (conscientiousness) (McCrae \& Costa, 1987), agreeableness and conscientiousness are traits that may sensitive employees to incivility, a stressor that can be viewed as directly challenging these values. Additionally, extraverted employees may secure social resources that distinctively enable them to manage this stressor, reducing their strains. By 
examining these traits, our study paints a broader picture of the role of FFM traits in relation to incivility, and more generally, the stressor-stain relationship.

Our research also furthers understanding of how personality and stressors contribute to emotional exhaustion and perpetrated incivility. Because research on perpetrated incivility is still in its nascent stages, little is known about the role of personality traits in determining whether individuals will perpetrate uncivil acts. As such, this study contributes to the theoretical understanding of the factors that lead employees to perpetrate incivility toward others and how personality traits may facilitate the spiral of incivility (i.e., those who experience incivility become perpetrators of incivility; Andersson \& Pearson, 1999) within an organization.

Finally, our research questions have practical implications for managers and organizations. We highlight two strains, emotional exhaustion and perpetrated incivility, which due to their relevance to employee performance and interpersonal interactions in the workplace, have important repercussions for customers, coworkers, and the broader organization. We also shed light on whether workers with certain personality traits may be differentially sensitive to incivility, enabling managers to take steps to address these sensitivities.

\section{Theoretical Framework}

\section{Conceptualizing Incivility and its Outcomes within a Stressor-Strain Framework}

Stressors refer to environmental factors that require an adaptive response and have the potential to result in poor psychological and physical health, as well as maladaptive behaviors (Bowling \& Jex, 2013). The stressor-strain framework (Spector, 1998; Spector \& Jex, 1998) proposes that exposure to stressful events in the workplace (stressors) leads employees to experience negative psychological, physical, or behavioral responses (strains). This framework provides a useful basis for understanding the relationship between incivility and its outcomes 
(see Penney \& Spector, 2005; Welbourne \& Sariol, 2017). Incivility is a significant source of stress for employees (Cortina et al., 2001) that can lead to negative psychological (Lim, Cortina, \& Magley, 2008) and behavioral (Gallus et al., 2014; Welbourne \& Sariol, 2017) responses.

In the current study, we focus on emotional exhaustion and perpetrated incivility as psychological and behavioral strains associated with incivility. Targets of incivility often experience emotional exhaustion (Rhee et al., 2017; van Jaarsveld et al., 2010), which is a dimension of burnout (Shirom, 1989, 2003). Because our study aims to emphasize outcomes that are directly relevant to how employees interact effectively with others in the organization, we draw from Shirom's $(1989,2003)$ conceptualization and measurement of emotional exhaustion as a depletion of emotional energy manifesting in an inability to show empathy to clients and customers, rather than the frequently used Maslach Burnout Inventory (Maslach, Jackson, \& Leiter, 1996), which conceptualizes exhaustion as feeling overextended and physically tired due to one's work. Shirom's conceptualization of burnout as a depletion of energy draws from Hobfoll's (1989; 2002) Conservation of Resources (COR) theory which postulates that individuals are motivated to obtain, retain, and protect resources they value. According to COR, stress occurs when individuals either lose (or face the threat of losing) valued resources or when they fail to gain key resources after expending effort to do so. In the context of burnout, Shirom (2010) focuses on energy resources, which are internally possessed and enable individuals to develop and utilize other resources. As workers use their emotional energy to cope with occupational stressors (e.g., incivility) their resources deplete, leading to emotional exhaustion, which negatively impacts work attitudes and performance (Cropanzano, Rupp, \& Byrne, 2003).

Stressors also trigger maladaptive behavioral responses (i.e., behavioral strains). Negative work behaviors frequently occur in response to stressors and may serve as employee coping 
responses to stressful work events (Spector \& Fox, 2002). In the context of incivility, employees may respond to experienced incivility by perpetrating incivility toward others (Gallus et al., 2014), leading it to "spiral" within an organization (Andersson \& Pearson 1999). Perpetrated incivility is maladaptive for employees and organizations (Porath \& Pearson, 2013), due to its negative psychological, behavioral, and health impacts (Cortina et al., 2001; Lim et al., 2008).

\section{Personality Influences on Incivility and the Stressor-Strain Relationship}

Bowling and Jex (2013) argue that a more nuanced understanding of the relationship between organizational stressors and strains can be gained by investigating the role of personality within this framework. Specifically, personality traits impact how employees experience and respond to stressors through multiple mechanisms. Personality may influence interpretations of the work environment (perception), self-selection into work environments, shaping of the work environment (stressor-creation) and differential sensitivity to stressors. The differential sensitivity hypothesis (Spector et al., 2000) proposes that personality traits can strengthen or weaken the relationship between workplace stressors and strains by making employees more (hypersensitivity effect) or less (hyposensitivity effect) sensitive to stressors.

Investigations into the role of personality in the stressor-strain relationship (Bowling \& Jex, 2013) converge with recent inclusion of individual differences, such as personality traits, into models of workplace incivility (Cortina et al., 2017). The nascent body of research on how personality influences experiences of incivility has taken two primary directions. The first examines whether personality traits influence exposure and perceptions of incivility, For example, Milam and colleagues (2009) found that employees high in neuroticism and low in agreeableness were most likely to provoke incivility. Sliter and Jones (2016) also found that neurotic and disagreeable employees reported experiencing more incivility from customers. 
Further, neurotic and conscientious employees were more likely to view uncivil behaviors as rude, whereas agreeable employees were less likely to do so (Sliter et al., 2015). A second stream of research investigates whether responses to incivility vary based on the target's personality, aligning with Spector et al.'s (2000) differential sensitivity hypothesis. Consistent with the broader occupational stress literature (Bowling \& Jex, 2013), incivility researchers have focused on the role of neuroticism in responses to incivility, finding that neurotic employees are more likely to report negative end-of-the day affect (Zhou et al., 2015), seek support from others (Beattie \& Griffin, 2014), avoid and behave negatively toward perpetrators of incivility (Beattie \& Griffin, 2014), and engage in aggressive workplace behavior (Taylor \& Kluemper, 2012) when they experience incivility. Although conscientious employees were less likely to respond to incivility with aggression (Taylor and Kluemper, 2012), they were more likely to experience reduced affective commitment to their organization (Taylor et al., 2012), suggesting that this trait may also be associated with heightened sensitivity to experiences of workplace incivility.

In addition to moderating the stressor-strain relationship, FFM personality traits have also been examined in terms of their direct effects on the two strains (burnout, perpetrated incivility) examined here. Meta-analyses examining the relationship between burnout and personality (Alarcon, Eschleman, \& Bowling, 2009; You, Huang, Wang, \& Bao, 2015) indicate that extraversion, agreeableness, and conscientiousness are negatively related to the emotional exhaustion component of burnout, while neuroticism is positively associated with emotional exhaustion. On the other hand, research examining FFM traits in relation to perpetrated workplace incivility is relatively scarce, with (to our knowledge) only two studies on this topic, one focusing on cyber-incivility (Krishnan, 2016) and the other on uncivil meeting behavior 
(Odermatt et al., 2018). Results varied across the two studies, specifically in relation to agreeableness and conscientiousness as predictors of perpetrated incivility.

\section{Hypotheses Development}

\section{Agreeableness as a Moderator between Incivility and Strains}

Agreeableness describes individuals who are kind and caring and engage in cooperative behavior (McCrae \& Costa, 1987). Highly agreeable individuals show concern for others and dislike interpersonal conflict (McCrae \& Costa, 1987). Although Bowling and Jex (2013) suggest that agreeableness may buffer employees against work stressors, we argue that in the context of incivility, highly agreeable employees are more likely to experience psychological strain. Because agreeable individuals are highly considerate in their own interpersonal interactions (McCrae \& Costa, 1987), they are likely to experience a lack of reciprocity when others act rudely and disrespectfully toward them. As such, they may be especially likely to view incivility targeted at them as unfair or unjust. Further, due to the value that agreeable individuals place on harmony and considerate behavior (McCrae \& Costa, 1987), they may be especially troubled by uncivil behavior that violates these standards. Because agreeable employees experience incivility as unjust, inconsistent with their own behavior, and contrary to their deep values of harmony and cooperativeness, we argue that they will experience greater emotional exhaustion when encounter this behavior, manifesting in an inability to connect and empathize with others around them (Shirom \& Melamed, 2006).

H1: Agreeableness moderates the relationship between incivility and emotional exhaustion, such that this relationship is stronger for workers who score higher on agreeableness than for workers who score lower on this trait. 
Although we expect agreeable individuals to experience more psychological strain in response to incivility, we argue, conversely, that they will be less likely to engage in maladaptive behavioral responses to incivility. Some support for this is found by Taylor and Kluemper (2012) who found that highly agreeable individuals were less likely to respond aggressively to incivility. More broadly, studies support that highly agreeable workers engage in less interpersonal deviance (Mount, Ilies, \& Johnson 2006). Because agreeable individuals show kindness and consideration to others (McCrae \& Costa, 1987) and are less likely to engage in interpersonal deviance (Mount et al., 2006), we argue that they will be less likely than their less agreeable counterparts to perpetrate incivility in response to experiencing incivility from others.

H2: Agreeableness moderates the relationship between experiencing incivility and perpetrating incivility, such that this relationship is weaker for workers scoring higher on agreeableness than for workers scoring lower on this trait.

\section{Conscientiousness as a Moderator between Incivility and Strains.}

Conscientiousness describes individuals who are goal-focused, responsible, and disciplined (McCrae \& Costa, 1990). We propose that conscientious workers experience greater emotional exhaustion in response to incivility than their less conscientious counterparts. Conscientious individuals are disciplined about adherence to rules (McCrae \& Costa, 1990), and incivility is behavior that clearly violates the workplace norms for respect (Andersson \& Pearson, 1999). Conscientious employees may also set exceptionally high standards for their coworkers to meet (Bowling \& Jex, 2013), leading to greater strain when these standards are not met. Indeed, conscientious individuals perceive uncivil behavior as more rude compared to those who are less conscientious (Sliter et al., 2015) and are more likely to reduce their affective commitment in response to incivility (Taylor et al., 2012), suggesting greater strain. We argue 
that because highly conscientious employees set high standards for their coworkers' behavior and value adherence to rules, they will experience a violation of these standards when coworkers act uncivilly toward them. The failure of coworkers to uphold their imposed standards and adhere to organizational norms of respect will enhance the psychological strain of incivility, resulting in increased emotional exhaustion.

H3: Conscientiousness moderates the relationship between incivility and emotional exhaustion, such that this relationship is stronger for workers who score higher on conscientiousness than for workers who score lower on this trait.

While we expect conscientiousness to increase the emotional exhaustion that workers experience in response to incivility, we argue that conscientiousness will reduce maladaptive behavioral responses to incivility. Conscientious individuals are disciplined and strive to follow rules (McCrae \& Costa, 1990). Indeed, conscientious workers are less likely to engage in counterproductive work behaviors (Mount et al., 2006) and to behave aggressively in response to incivility (Taylor and Kluemper, 2012). As such, we suggest that conscientious employees will be less likely to perpetrate incivility toward others in response to being targeted by incivility. H4: Conscientiousness moderates the relationship between experiencing incivility and perpetrating incivility toward others, such that this relationship is weaker for workers who score high on conscientiousness than for workers scoring low on this trait.

\section{Neuroticism as a Moderator between Incivility and Strains}

Neuroticism describes individuals who are predisposed to experiencing negative affect (McCrae \& Costa, 1990). Individuals who score high on this trait dimension are fearful, anxious, insecure, and tend to perceive environmental stimuli in negative and threatening ways (McCrae \& John, 1992). From the FFM, neuroticism is the trait most frequently studied in connection to 
workplace stress (Bowling \& Jex, 2013), because it is associated with greater exposure and reactivity to stressors (Bolger \& Zuckerman, 1995). Indeed, some studies find that employees high in neuroticism experience stronger relationships between workplace stressors and strains (Bowling \& Jex, 2013). Applying a resource-based conceptualization of burnout (Hobfoll, 1989; Shirom, 1989; 2003), neurotic individuals consume more resources responding to workplace stressors and consequently experience a depletion of emotional energy (Armon, Shirom, \& Melamed, 2012; Connor-Smith and Flachsbart, 2007). Consistent with this, past studies find that neurotic employees report encountering more incivility (Milam et al., 2009; Sliter et al., 2015), perceive incivility as more rude (Sliter et al., 2015), and experience greater negative affect in response to this stressor (Zhou et al., 2015). As such, we propose that employees high in neuroticism will experience greater emotional exhaustion in response to incivility.

H5: Neuroticism moderates the relationship between incivility and emotional exhaustion, such that this relationship is stronger for workers who score higher on neuroticism than for workers who score lower on this trait.

Research suggests that employees high in neuroticism are more likely than their more emotionally stable counterparts to engage in negative behavioral responses to stressors. For example, employees high in neuroticism were found to engage in more aggressive behavior following exposure to incivility (Taylor \& Kluemper, 2012) and behave more negatively toward perpetrators of incivility (Beattie \& Griffin, 2014). Therefore, we hypothesize that employees high in neuroticism will be more likely to perpetrate incivility when targeted by incivility.

H6: Neuroticism moderates the relationship between experiencing incivility and perpetrating incivility, such that this relationship is stronger for workers who score higher on neuroticism than for workers who score lower on this trait. 


\section{Extraversion as a Moderator between Incivility and Strains}

Extraverted individuals are sociable, friendly, talkative, and enthusiastic (McCrae and

Costa, 1990). As such, they may be better able to amass resources (Hobfoll, 1989; 2002), such as increased social support, that have the potential to buffer or protect them against workplace stressors (Bowling \& Jex, 2015). The link between extraversion and increased social support has been well-documented, indicating that extraverts perceive greater availability of social support, receive more support from others, and have larger and more diverse support networks (Swickert, Rosentreter, Hittner, \& Mushrush, 2002). We argue that the characteristics associated with extraversion may be particularly relevant to coping with incivility. Past research suggests that individuals whose cultural values promote sociability and warm relationships experience less burnout in response to incivility (Welbourne, Gangadharan, \& Sariol, 2015) and that social support buffers workers against the negative impacts of incivility (Miner, Settles, Pratt-Hyatt, \& Brady, 2012). Drawing from a resource-based conceptualization of burnout (Hobfoll, 1989; Shirom, 1989; 2003), we argue that because extraversion is associated with the ability to accumulate resources, such as social support, that may buffer against incivility, extraverted employees will be less likely to experience emotional exhaustion in response to this stressor.

H7: Extraversion moderates the relationship between incivility and emotional exhaustion, such that this relationship is weaker for workers who score higher on extraversion than for workers who score lower on this trait.

Because we expect extraversion to provide employees with greater availability of resources (e.g., social support) that reduce the strains associated with incivility, we predict that highly extraverted employees will be better able to cope with this stressor. Therefore, they will be less likely to engage in maladaptive behavioral responses that may occur as coping responses 
(Spector \& Fox, 2002) to incivility. Accordingly, we predict that extraversion will weaken the relationship between experienced incivility and perpetrated incivility.

H8: Extraversion moderates the relationship between experiencing incivility and perpetrating incivility, such that this relationship is weaker for workers who score higher on extraversion than for workers who score lower on this trait.

\section{Method}

\section{Participants and Procedure}

Two waves of data were collected from working adults in the United States. The sample of participants who took part in the current study participated in a broader 2-wave study of incivility experiences that was conducted by the first author (Welbourne \& Sariol, 2017). None of the variables (other than reported incivility and control variables) that were examined in the previous study are included in the hypothesis testing for the current study. Respondents were recruited using the "audience" feature of Survey Monkey, an online survey vendor. Through this function, the survey vendor administrators directly recruited participants who met our research criteria (full-time employed, United States workers) from their database of more than 30 million registered users who volunteer to complete surveys monthly in exchange for small non-cash incentives. An initial sample of 500 respondents who met the screening requirements of having a full-time job were recruited for the first wave of data collection. These respondents were contacted six weeks later through the survey vendor to participate in a second wave of the survey. During the first wave of the survey (Time 1), we measured incivility (experienced by the participant), personality characteristics and demographic/control variables. During the second wave (Time 2), we assessed the dependent variables of emotional exhaustion and perpetrated incivility. Participants had an opportunity to select a charity to receive a small donation (from the 
survey vendor) in exchange for their response to both the surveys. Institutional review board (IRB) approval was obtained prior to conducting the study.

A total of 252 respondents (50\% male) completed surveys at both waves, with an average age of 45.9 years. Participants reported working for an average of 8.75 years $(S D=8.99)$ at their respective organizations. A majority of them belonged to the service sector (26.4\%) followed by administrative (15.2\%), technical (11.2\%), education (10\%) and medical/health $(9.2 \%)$ job sectors. More than half of the respondents (53.2\%) reported spending between 40-49 hours per week at work. A majority of participants were White/Caucasians (77.2\%). The remaining participants indicated that they were Black/African-American (10\%), Asian/Pacific Islander (6.8\%), Hispanic (3.2\%), American Indian/Eskimo (.4\%) or indicated other ethnicity (1.2\%).

\section{Measures}

Experienced Workplace Incivility. We used Cortina et al.'s (2001) 7-item scale to measure the frequency with which participants experienced incivility. Participants reported how often they experienced uncivil behaviors during last six months using a 5-point response format ranging from "never" to "very often". A sample item is: "Have you been in a situation where any of your superiors or coworkers ignored or excluded you from professional camaraderie?"

Big 5 Personality Traits. The traits of agreeableness, conscientiousness, neuroticism, and extraversion were assessed with subscales from the 20-item Mini IPIP (Donnellan, Oswald, Baird, \& Lucas, 2006), a shortened form of the 50-item International Personality Item Pool (IPIP) that is based on the FFM (McCrae \& John, 1992). Participants rated how well each item described them using a 5-point response format ("strongly disagree" to "strongly agree"). Sample items from each of the 4-item subscales are as follows: "I sympathize with others' 
feelings" (agreeableness); "I get chores done right away" (conscientiousness); "I talk to a lot of different people at parties" (extraversion); and "I get upset easily" (neuroticism).

Emotional Exhaustion. Emotional exhaustion was assessed with the 3-item emotional exhaustion subscale of the Shirom-Melamed Burnout Measure (SMBM) (Shirom et al., 2005). A sample item is: "I feel I am unable to be sensitive to the needs of coworkers and customers". Participants rated (on a 5-point scale of "never" to "always") how often they felt that way in the past 30 days of work.

Perpetrated Incivility. We adapted Cortina et al.'s (2001) 7-item workplace incivility scale to assess perpetrated incivility. We modified the language of the items to allow participants to report perpetrated, rather than experienced incivility (e.g., "Put down others or were condescending to them in some way"). Respondents indicated on a 5-point scale ("never" to "very often") how frequently they engaged in each behavior during the past 30 days at work.

Control and Demographic Variables. Participants reported their gender, ethnicity, and number of hours worked per week, which were included as control variables in all analyses due to their association with our central variables. Specifically, gender has been associated with experienced (Cortina et al., 2002) and perpetrated (Koon \& Pun, 2018) incivility, as well as emotional exhaustion (Worly, Verbeck, Walker, \& Clinchot, 2019). Additionally, ethnicity is associated with experienced incivility (Welbourne et al., 2015) and longer work hours with emotional exhaustion (Kunaviktikul et al., 2015). In addition to the above control variables, participants reported their job sector and length of tenure with the organization.

\section{Results}

Descriptive and internal consistency statistics for all measures are reported in Table 1. We conducted moderated hierarchical regression analysis (Aiken \& West, 1991) to test our 
hypotheses regarding personality traits as moderators of the relationship between experienced incivility (stressor) and emotional exhaustion and perpetrated incivility (strains). The results of these analyses are reported in Table 2 . Incivility and all four personality traits were transformed into standardized z-scores from which we computed interaction terms (Aiken \& West, 1991). Control variables were entered in Step 1 of the regression. Main effects were entered in Step 2, followed by two-way interaction terms (incivility x personality trait) in Step 3. Statistically significant interactions were plotted with means estimated at high (+1 SD) and low (-1 SD) levels of each interaction term. Additionally, we examined the regions of significance for significant interactions, employing the Johnson-Neyman (JN) technique (Spiller, Fitzsimons, Lynch, \& McClelland, 2013; Bauer \& Curran, 2005) using the R package "probemode" (Tan, 2015).

Consistent with prior research, experienced incivility (at Time 1) predicted emotional exhaustion $(\beta=.38, \mathrm{p}<.01)$ and perpetrated incivility $(\beta=.49, \mathrm{p}<.01)$ [at Time 2 ]. As predicted (H1), agreeableness moderated the relationship between incivility and emotional exhaustion $(\beta=.17, \mathrm{p}<.05)$. Simple slope analyses indicate that respondents who scored high on agreeableness were more likely to experience emotional exhaustion $(\mathrm{B}=.53, \mathrm{t}=5.88, \mathrm{p}<$ $.001)$ in response to incivility than employees who scored low on this personality dimension $(\mathrm{B}=$ $.20, \mathrm{t}=2.26, \mathrm{p}<.05)$ [see Figure 1]. Probing this interaction further with the $\mathrm{J}-\mathrm{N}$ technique indicates that for participants with agreeableness scores that were 2.6 SD or more below the sample mean, experienced incivility was not related to emotional exhaustion; for participants with agreeableness scores higher than this, experienced incivility was associated with emotional exhaustion. 
Agreeableness moderated the relationship between incivility and perpetrated incivility $(\beta=.14, \mathrm{p}<.05)$; however, the relationship was counter to our prediction $(\mathrm{H} 2)$, such that the relationship between experienced and perpetrated incivility was stronger for highly agreeable employees $(\mathrm{B}=.49, \mathrm{t}=6.87, \mathrm{p}<.001)$ than for employees who scored lower on this personality trait $(\mathrm{B}=.27, \mathrm{t}=3.76, \mathrm{p}<.01)$ [See Figure 2]. Probing this interaction with the $\mathrm{J}-\mathrm{N}$ technique indicates that the association between experienced and perpetrated incivility is significant at all levels of the moderator. Thus, the relationship between experienced and perpetrated incivility is stronger for participants with higher agreeableness scores, but still significant for participants with lower agreeableness scores.

Conscientiousness moderated the relationship between incivility and emotional exhaustion $(\beta=-.24, \mathrm{p}<.01)[\mathrm{H} 3]$. This was in a direction opposite to our predictions, such that the relationship between incivility and emotional exhaustion was stronger for employees who scored low in conscientiousness $(B=.58, t=6.53, \mathrm{p}<.001)$ than for employees who were highly conscientious $(\mathrm{B}=.14, \mathrm{t}=1.61, \mathrm{~ns})$ [see Figure 3]. Probing this interaction with the $\mathrm{J}-\mathrm{N}$ technique indicates that for participants with conscientiousness scores that were 1.2 SD or more above the sample mean, experienced incivility was not related to emotional exhaustion; for participants with conscientiousness scores lower than this, experienced incivility was associated with emotional exhaustion.

In support of $\mathrm{H} 4$, conscientiousness moderated the relationship between incivility and perpetrated incivility $(\beta=-.31, \mathrm{p}<.01)$ such that the relationship between experiencing incivility and perpetrating incivility was stronger for employees who scored low on conscientiousness $(\mathrm{B}=$ $.62, \mathrm{t}=8.78, \mathrm{p}<.001)$ than for employees who were highly conscientious $(\mathrm{B}=.13, \mathrm{t}=1.85, \mathrm{p}=$ .07). [See Figure 4]. Probing this interaction, participants with conscientiousness scores that were 
1.3 SD or more above the sample mean, experienced incivility was not related to perpetrated incivility; for participants who scored lower on conscientiousness, experienced incivility was associated with perpetrated incivility. There were no moderating effects of neuroticism [H5/6] or extraversion [H7/8] on the examined relationships (see supplemental materials for additional analyses examining these traits).

\section{Discussion}

This study aimed to investigate the degree to which workers' personality traits influenced their sensitivity to the stressor of workplace incivility, a low-impact form of interpersonal deviance. Past research indicates that targets of incivility experience detrimental psychological outcomes, such as emotional exhaustion (Kern \& Grandey, 2009; Rhee et al., 2017; van Jaarsveld et al., 2010) and engage in maladaptive behavioral responses, such as perpetrating incivility toward others (Gallus et al., 2014). We investigated whether agreeableness, conscientiousness, neuroticism, and extraversion moderated the relationship between experienced incivility and these two strains: emotional exhaustion and perpetrated incivility. Partial support was found for our hypotheses, as we discuss in more detail below.

As predicted, employees who were highly agreeable experienced stronger relationships between incivility and emotional exhaustion, compared to those who scored lower on this trait. Highly agreeable employees may be especially likely to experience stress when they are treated uncivilly, because this behavior is inconsistent with their desire for harmony and cooperation (McCrae \& Costa, 1987). Agreeableness describes individuals who are kind and show concern for others (Costa \& McCrae, 1992), whereas uncivil behavior, which is rude and disrespectful, starkly contrasts these standards. Unexpectedly, we found that highly agreeable workers were also more likely to perpetrate incivility in response to this stressor. This finding is counter- 
intuitive, because such behavior appears at odds with the considerate nature of agreeable employees. Further, it contrasts with Taylor and Kluemper's (2012) finding that agreeable employees were less likely to respond to incivility with aggression. This suggests that while agreeable employees avoid engaging in overtly aggressive behavior, they turn to more subtle forms of interpersonal deviance in response to experiencing incivility. One potential explanation is that because agreeable individuals treat others with kindness, they are more likely to perceive uncivil behavior toward themselves as unjust or undeserved. Perceived injustice has been found to trigger anger (Haidt, 2003), which is an antecedent of interpersonal deviance (Spector \& Fox, 2002). Overall, our findings highlight that agreeableness is associated with heightened sensitivity to experienced incivility. Further research might explore whether other outcomes of incivility are similarly strengthened for agreeable employees.

Counter to our prediction, conscientious employees were less likely to experience emotional exhaustion in response to incivility compared to those who were less conscientious. Emotional exhaustion manifests as an employee's loss of strength to show empathy and concern to customers and coworkers (Shirom et al., 2005). It is possible that because conscientiousness individuals are disciplined, dutiful, and hardworking (McCrae \& Costa, 1987), they did not let incivility influence their work performance, in terms of serving customers well. Further, as expected, conscientious employees were less likely to perpetrate incivility in response to experiencing incivility. This is consistent with the discipline associated with conscientiousness (McCrae \& Costa, 1987) and the finding that conscientious employees are less likely to react aggressively to experienced incivility (Taylor \& Kluemper, 2012). Our results thus suggest that when targeted by incivility, highly conscientious employees are able to remain civil to those around them and continue to show empathy and concern to customers and coworkers. 
Our predictions that neuroticism would strengthen the relationships between experienced incivility and emotional exhaustion and perpetrated incivility were not supported. Although our findings contrast with past work suggesting that neuroticism moderates the stressor-strain relationship (Bolger \& Zuckerman, 1995), Bowling and Jex (2013) note that several occupational stress studies have failed to find interactive effects of neuroticism on the relationship between stressors and strains. However, because neuroticism has been found to influence other responses to incivility, such as displaying overtly aggressive behavior (Taylor \& Kluemper, 2012) and engaging in coping behaviors (Beattie \& Griffin, 2014), we suggest that future work continue to examine its moderating role for other incivility outcomes.

Finally, our prediction that extraversion would buffer employees against the psychological and behavioral strains associated with experienced incivility was not supported. This suggests that extraversion does not play a significant role in determining employees' sensitivity to workplace incivility, at least for the emotional exhaustion and perpetrated incivility outcomes examined here. This conclusion is further supported by the nonsignificant zero-order correlation $(\mathrm{r}=.02, \mathrm{~ns})$ found between extraversion and perpetrated incivility. In light of these results, we encourage researchers to further explore whether extraversion influences other responses to incivility and whether the predicted buffering effects of this trait (Bowling \& Jex, 2013) occur for other types of stressors.

\section{Theoretical Implications}

Our study aligns with the recent emphasis in incorporating individual differences, such as personality traits, within models of workplace incivility (Cortina et al., 2017). In particular, our findings highlight that agreeableness may sensitize employees to the impacts of incivility. Although past research has examined how agreeableness influences exposure to incivility 
(Milam et al., 2009; Sliter \& Jex, 2016), there has been little exploration of how this personality trait influences responses to incivility. Our findings suggest that agreeable employees experience heightened impacts of this stressor on their ability to show empathy and concern to customers (emotional exhaustion), as well as engage in behavioral responses (i.e., perpetrated incivility) that are detrimental to the organization. Our study also provides a more nuanced understanding of how conscientiousness might influence employee responses to incivility. While past research suggests that conscientiousness enhances perceptions of the rudeness of incivility (Sliter et al., 2015), resulting in lower job attitudes (Taylor et al., 2012), our findings indicate that conscientiousness may have a silver lining for the organization through the enhanced discipline displayed by conscientious employees when they experience incivility. Specifically, our study suggests that highly conscientious employees do not allow incivility to negatively impact their interactions with employees and customers.

Our study also adds to the broader understanding of personality's role within the stressorstrain theoretical framework. First, by taking a more comprehensive approach to examining FFM traits (McCrae \& John, 1992) in our study, we address Bowling and Jex's (2013) suggestion that researchers broaden their scope to examine other Big Five personality traits in addition to neuroticism in relation to occupational stressors. Second, our findings provide further empirical testing of Spector et al.'s (2000) differential sensitivity hypothesis. Our results suggest that agreeableness increased employee sensitivity to incivility, whereas conscientiousness decreased sensitivity to this stressor. Interestingly, some of our results contrast the extant literature. For instance, both agreeableness and extraversion have been linked to resources that buffer employees against the strains of workplace stressors (e.g., Bowling \& Jex, 2013). However, we found that extraversion did not reduce strains associated with incivility, whereas, agreeableness 
enhanced them. This suggests that the role of personality traits in moderating the stressor-strain relationship may vary across different categories of stressors and may benefit from being investigated in this way. For example, agreeableness may sensitize employees to stressors that are interpersonal, but reduce their sensitivity to other stressors (e.g., workload or role-based).

\section{Practical Implications}

Our finding that personality traits influence employees' sensitivity to experienced incivility leads to several managerial implications. First, because highly agreeable employees are more likely to experience emotional exhaustion and perpetrate incivility in response to experienced incivility, it is important for managers to be aware of this and provide the appropriate intervention and support for highly agreeable employees. Second, we suggest that managers make strategic staffing and deployment decisions based on employees' personality traits. Because highly conscientious employees are less likely to report emotional exhaustion and perpetrate incivility in response to experienced incivility, such individuals may be the first logical choice for jobs that involve customer contact and exposure to incivility. In contrast, highly agreeable employees, who experienced a heightened association between incivility and emotional exhaustion, may struggle to perform work that involves customer contact when they are in an environment in which they are exposed to incivility. Finally, the strong association of incivility with emotional exhaustion and perpetrated incivility in our study underscores the importance of taking organizational steps to reduce incivility in the workplace. Past studies suggest that interventions, such as incivility training (Leiter, Laschinger, Day, \& Oore, 2011), as well establishing and implementing consequences for incivility (Cortina, 2008), may deter employees from engaging in this form of interpersonal deviance.

\section{Limitations and Future Directions}


While the current study provides insights into how personality influences employees' responses to incivility, it has some limitations. Data was self-reported and collected from a single source, creating potential for bias due to common method variance. Although most of our constructs focus on workers' subjective experiences (e.g., experienced incivility, emotional exhaustion) and as such are best reported by the respondent rather than an outside source, future research may benefit from collecting both self and other ratings of personality. To reduce concerns of common method bias we took steps to separate our predictor and outcome variables (data was collected in two waves) and emphasized anonymity of responses (Podsakoff, MacKenzie, Lee, \& Podsakoff, 2003). Further, we examined interaction effects, which are less subject to common method bias (Siemsen, Roth, \& Oliveira, 2010). Another limitation is the lack of ethnic and cultural diversity of our sample. Approximately $80 \%$ of participants identified as White/Caucasian, and respondents came from a single country (United States). Further research should consider sampling respondents who vary more broadly on these dimensions to examine generalization of our findings. Finally, we focused only on personality traits from the FFM (McCrae \& John, 1992). We encourage future research to examine other traits that may influence employee sensitivity to incivility, as well as interactive effects of the FFM trait dimensions, a direction largely unexplored in occupational stress research (Bowling \& Jex, 2013).

\section{Conclusion}

The current study contributes to workplace incivility and organizational stress literatures by investigating the influence of personality traits on behavioral and psychological responses to incivility. Our findings suggest that some FFM personality traits mitigate the negative strains associated with incivility, while others strengthen them. We encourage future research to further investigate how personality relates to individual and organizational outcomes of incivility. 


\section{References}

Aiken, L.S., \& West, S.G. (1991). Multiple regression: Testing and interpreting interactions. Newbury Park: Sage.

Alarcon, G., Eschleman, K. J., \& Bowling, N. A. (2009). Relationships between personality variables and burnout: A meta-analysis. Work \& Stress, 23(3), 244-263. https://doi.org/10.1080/02678370903282600

Andersson, L. M., \& Pearson, C. M. (1999). Tit for tat? The spiraling effect of incivility in the workplace. Academy of Management Review, 24, 452-471. https://doi.org/10.2307/259136

Armon, G., Shirom, A., \& Melamed, S. (2012). The Big Five personality factors as predictors of changes across time in burnout and its facets. Journal of Personality, 80, 403-427. https://doi.org/10.1111/j.1467-6494.2011.00731.x

Bauer, D. J., \& Curran, P. J. (2005). Probing interactions in fixed and multilevel regression: Inferential and graphical techniques. Multivariate Behavioral Research, 40(3), 373-400. https://doi.org/10.1207/s15327906mbr4003_5

Beattie, L., \& Griffin, B. (2014). Accounting for within-person differences in how people respond to daily incivility at work. Journal of Occupational and Organizational Psychology, 87, 625-644. https://doi.org/10.1111/joop.12067

Bolger, N., \& Zuckerman, A. (1995). A framework for studying personality in the stress process. Journal of Personality and Social Psychology, 69, 890-902. https://doi.org/10.1037/0022-3514.69.5.890

Bowling, N.A., \& Jex, S.M. (2013). The role of personality in occupational stress: A review and future research agenda. In N.D. Christiansen \& R.A. Tett (Eds.), Handbook of personality at work (692-717). New York: Routledge.

Connor-Smith, J. K., \& Flachsbart, C. (2007). Relations between personality and coping: A meta-analysis. Journal of Personality and Social Psychology, 93, 1080-1107. http://doi.org/10.1037/0022-3514.93.6.1080

Cortina, L.M. (2008). Unseen injustice: Incivility as modern discrimination in organizations. Academy of Management Review, 33, 55-75. https://doi.org/10.5465/amr.2008.27745097

Cortina, L. M., Lonsway, K. A., Magley, V. J., Freeman, L. V., Collinsworth, L. L., Hunter, M., \& Fitzgerald, L. F. (2002). What's gender got to do with it? Incivility in the federal courts. Law \& Social Inquiry, 27, 235-270. https://doi.org/10.1111/j.17474469.2002.tb00804.x 
Cortina, L.M., Kabat-Farr, D., Magley, V.J., \& Nelson, K. (2017). Researching rudeness: The past, present, and future of the science of incivility. Journal of Occupational Health Psychology, 22, 299-313. http://dx.doi.org/10.1037/ocp0000089

Cortina, L. M., Magley, V. J., Williams, J. H., \& Langhout, R. D. (2001). Incivility in the workplace: Incidence and impact. Journal of Occupational Health Psychology, 6, 64-80. https://doi.org/10.1037/1076-8998.6.1.64

Costa, P.T., \& McCrae, R.R. (1992). Revised NEO personality inventory (NEO-PI-R) and NEO five-factor inventory (NEO-FFI) professional manual. Odessa, Florida: Psychological Assessment Resources.

Cropanzano, R., Rupp, D.E., \& Byrne, Z.S. (2003). The relationship of emotional exhaustion to work attitudes, job performance, and organizational citizenship behaviors. Journal of Applied Psychology, 88(1), 160-169.

Donnellan, M.B., Oswald, F.L., Baird, B.M., \& Lucas, R.E. (2006). The mini-IPIP scales: Tinyyet-effective measures of the big five factors of personality. Psychological Assessment, 18, 192-203. https://doi.org/10.1037/1040-3590.18.2.192

Gallus, J.A., Matthews, R.A., Bunk, J.A., Barnes-Farrell, J.L., \& Magley, V.J. (2014). An eye for an eye? Exploring the relationship between workplace incivility experiences and perpetration. Journal of Occupational Health Psychology, 19, 143-154.

https://doi.org/10.1037/a0035931

Grant, S., \& Langan-Fox, J. (2007). Personality and the occupational stressor-strain relationship: The role of the Big Five. Journal of Occupational Health Psychology, 12, 20-33. https://doi.org/10.1037/1076-8998.12.1.20

Haidt, J. (2003). The moral emotions. In R.J. Davidson, K.R. Scherer, \& H.H. Goldsmith (Eds.), Handbook of Affective Sciences (852-870). New York: Oxford University Press.

Hobfoll, S.E. (1989). Conservation of resources: A new attempt at conceptualizing stress. American Psychologist, 44(3), 513-524. https://doi.org/10.1037/0003-066x.44.3.513

Hobfoll, S.E. (2002). Social and psychological resources and adaptation. Review of General Psychology, 6, 307-324. http://dx.doi.org/10.1037/1089-2680.6.4.307

Kern, J. H. \& Grandey, A. A. (2009). Customer incivility as a social stressor: The role of race and racial identity for service employees. Journal of Occupational Health Psychology, 14(1), 46-57. https://doi.org/10.1037/a0012684

Koon, V-Y., \& Pun, P-Y. (2018). The mediating role of emotional exhaustion and job satisfaction on the relationship between job demands and instigated workplace incivility. The Journal of Applied Behavioral Science, 54(2), 187-207.

https://doi.org/10.1177\%2F0021886317749163 
Krishnan, S. (2016). Electronic warfare: A personality model of cyber incivility. Computers in Human Behavior, 64, 537-546. https://doi.org/10.1016/j.chb.2016.07.031

Kunaviktikul, W., Wichaikhum, O., Nantsupawat, A., Nantsupawat, R., Chontawan, R., Klunklin, A., ... Sirakamon, S. (2015). Nurses' extended work hours: Patient, nurse, and organizational outcomes. International Nursing Review, 62, 386-393. https://doi.org/10.1111/inr.12195

Leiter, M. P., Laschinger, H. K. S., Day, A., \& Oore, D. G. (2011). The impact of civility interventions on employee social behavior, distress, and attitudes. Journal of Applied Psychology, 96, 1258-1274. https://doi.org/10.1037/a0024442

Lim, S., Cortina, L. M., \& Magley, V. J. (2008). Personal and workgroup incivility: impact on work and health outcomes. Journal of Applied Psychology, 93, 95-107. https://doi.org/10.1037/0021-9010.93.1.95

Maslach, C.M., Jackson, S.E., \& Leiter, M.P. (1996). Maslach burnout inventory manual (3 ${ }^{\text {rd }}$ edition). Palo Alto, CA: Consulting Psychologists Press.

McCrae, R.R., \& Costa, P.T. (1987). Validation of the five-factor model of personality across instruments and observers. Journal of Personality and Social Psychology, 52, 81-90. http://dx.doi.org/10.1037/0022-3514.52.1.81

McCrae, R.R., \& Costa, P.T. (1990). Personality in adulthood. New York: Guilford.

McCrae, R.R., \& John, O.P. (1992). An introduction to the five-factor model and its applications. Journal of Personality, 60, 175-215. https://doi.org/10.1111/j.1467-6494.1992.tb00970.x

Meier, L. L., \& Semmer, N. K. (2012). Lack of reciprocity, narcissism, anger, and instigated workplace incivility: A moderated mediation model. European Journal of Work and Organizational Psychology, 22, 461-475. DOI: http://dx.doi.org/10.1080/1359432X.2012.654605

Melamed, S., Shirom, A., Toker, S., Berliner, S., \& Shapira, I. (2006). Burnout and risk of cardiovascular disease: evidence, possible casual paths, and promising research directions. Psychological Bulletin, 132(3), 327-353. https://doi.org/10.1037/00332909.132.3.327

Milam, A.C., Spitzmueller, C., \& Penney, L.M. (2009). Investigating individual differences among targets of workplace incivility. Journal of Occupational Health Psychology, 14, 58-69. https://doi.org/10.1037/a0012683

Miner, K.N., Settles, I.H., Pratt-Hyatt, J.S., \& Brady, C.C. (2012). Experiencing incivility in organizations: The buffering effects of emotional and organizational support. Journal of Applied Social Psychology, 42, 340-372. https://doi.org/10.1111/j.1559$\underline{1816.2011 .00891 . x}$ 
Mount, M. Ilies, R., \& Johnson, E. (2006). Relationship of personality traits and counterproductive work behaviors: The mediating effects of job satisfaction. Personnel Psychology, 59, 591-622. DOI: https://doi.org/10.1111/j.1744-6570.2006.00048.x

Odermatt, I., Konig, C. J., Kleinmann, M., Bachmann, M., Order, H., \& Schmitz, P. (2018). Incivility in meetings: Predictors and outcomes. Journal of Business and Psychology, 33, 263-282. https://doi.org/10.1007/s10869-017-9490-0

Pearson, C.M., Andersson, L.M., \& Porath, C.L. (2005) Workplace incivility. In S. Fox \& P.E. Spector (Eds.), Counterproductive work behaviour: Investigations of actors and targets (177-200). Washington, DC: American Psychological Association.

Penney, L.M., \& Spector, P.E. (2005). Job stress, incivility, and counterproductive work behavior (CWB): The moderating role of negative affectivity. Journal of Organizational Behavior, 26, 777-796. https://doi.org/10.1002/job.335

Podsakoff, P.M., MacKenzie, S.B., Lee, J.Y., \& Podsakoff, N.P. (2003). Common method biases in behavioral research: A critical review of the literature and recommended remedies. Journal of Applied Psychology, 88, 879-903. https://doi.org/10.1037/0021-9010.88.5.879

Porath, C. L., \& Pearson, C. M. (2013). The price of incivility. Harvard Business Review, 91, 114-121.

Rhee, S-Y., Hur, W-M., \& Kim, M. (2017). The relationship of coworker incivility to job performance and the moderating role of self-efficacy and compassion at work: The job demands-resources (JD-R) approach. Journal of Business \& Psychology, 32, 711-726. https://doi.org/10.1007/s10869-016-9469-2

Shirom, A. (2010). Employee burnout and health: Current knowledge and future research paths. In J. Houdmont and S. Leka (Eds.), Contemporary Occupational Health Psychology (5977). U.K.: Wiley.

Shirom, A. (1989). Burnout in work organizations. In C.L. Cooper \& I. Roberston (Eds.), International Review of Industrial and Organizational Psychology (25-48). New York: Wiley.

Shirom, A., \& Melamed, S. (2006). A comparison of the construct validity of two burnout measures in two groups of professionals. International Journal of Stress Management, 13, 176-200. https://doi.org/10.1037/1072-5245.13.2.176

Shirom, A., Melamed, S., Toker, S., Berliner, S., \& Shapira, I. (2005). Burnout, mental and physical health: A review of the evidence and a proposed explanatory model. International Review of Industrial and Organizational Psychology, 20, 269-309. 
Siemsen, E. Roth, A., \& Oliveira, P. (2010). Common method bias in regression models with linear, quadratic, and interaction effects. Organizational Research Methods, 13, 456-476. https://doi.org/10.1177/1094428109351241

Sliter, M., \& Jones, M. (2016). A qualitative and quantitative examination of the antecedents of customer incivility. Journal of Occupational Health Psychology, 21, 208-219. http://dx.doi.org/10.1037/a0039897

Sliter, M., Sliter, K., \& Jex, S. (2012). The employee as a punching bag: The effect of multiple sources of incivility on employee withdrawal behavior and sales performance. Journal of Organizational Behavior, 33, 121-139. https://doi.org/10.1037/a0029862

Sliter, M., Withrow, S., \& Jex, S.M. (2015). It happened, or you thought it happened? Examining the perception of workplace incivility based on personality characteristics. International Journal of Stress Management, 22, 24-45. http://dx.doi.org/10.1037/a0038329

Spector, P. E. (1998). A control theory of the job stress process. In C. L. Cooper (Ed.), Theories of organizational stress (153-169). Oxford, England: Oxford University Press.

Spector, P.E., \& Fox, S. (2002). An emotion-centered model of voluntary work behavior. Human Resource Management Review, 12, 269-292. https://doi.org/10.1016/S10534822(02)00049-9

Spector, P.E., \& Jex, S.M. (1998). Development of four self-report measures of job stressors and strain: Interpersonal conflict at work scale, organizational constraints scale, quantitative workload inventory, and physical symptoms inventory. Journal of Occupational Health Psychology, 3, 356-367. https://doi.org/10.1037/1076-8998.3.4.356

Spector, P.E., Chen, P.Y., \& O’Connell, B.J. (2000). A longitudinal study of relations between job stressors and job strains while controlling for prior negative affective and strains. Journal of Applied Psychology, 85, 211-218. https://doi.org/10.1037/0021-9010.85.2.211

Spiller, S. A., Fitzsimons, G. J., Lynch, J. G., Jr., \& McClelland, G. H. (2013). Spotlights, floodlights, and the magic number zero: Simple effects tests in moderated regression. Journal of Marketing Research, 50(2), 277-288. https://doi.org/10.1509\%2Fjmr.12.0420

Swickert, R.J., Rosentreter, C.J., Hittner, J.B., \& Mushrush, J.E. (2002). Extraversion, social support processes, and stress. Personality and Individual Differences, 32, 877-891. https://doi.org/10.1016/S0191-8869(01)00093-9

Tan, J. C. (2015). Package “probemode.” https://cran.r-project.org/package=probemod

Taris, T. W. (2006). Is there a relationship between burnout and objective performance? A critical review of 16 studies. Work \& Stress, 20, 316-334. https://doi.org/10.1080/02678370601065893 
Taylor, S.G., \& Kluemper, D.H. (2012). Linking perceptions of role stress and incivility to workplace aggression: The moderating role of personality. Journal of Occupational Health Psychology, 17, 316-329. https://doi.org/10.1037/a0028211

Tremmel, S., \& Sonnentag, S. (2018). A sorrow halved? A daily diary study on talking about experienced workplace incivility and next-morning negative affect. Journal of Occupational Health Psychology, 23(4), 568-583. https://doi.org/10.1037/ocp0000100

van Jaarsveld, D. D., Walker, D. D., \& Skarlicki, (2010). The role of job demands and emotional exhaustion in the relationship between customer and employee incivility. Journal of Management, 36(6), 1486-1504. https://doi.org/10.1177/0149206310368998

Welbourne, J.L., Gangadharan, A., \& Sariol, A.M. (2015). Ethnicity and cultural values as predictors of the occurrence and impact of experience workplace incivility. Journal of Occupational Health Psychology, 20, 205-217. https://doi.org/10.1037/a0038277

Welbourne, J.L., \& Sariol, A.M. (2017). When does incivility lead to counterproductive work behavior? Roles of job involvement, task interdependence, and gender. Journal of Occupational Healthy Psychology, 22, 194-206. https://doi.org/10.1037/ocp0000029

Worly, B., Verbeck, N., Walker, C., \& Clinchot, D. M. (2019). Burnout, perceived stress, and empathic concern: differences in female and male millennial medical students. Psychology, Health, \& Medicine, 24(4), 429-438. https://doi.org/10.1080/13548506.2018.1529329

You, X., Huang, J., Wang, Y., \& Bao, X. (2015). Relationships between individual-level factors and burnout: A meta-analysis of Chinese participants. Personality and Individual Differences, 74, 139-145. http://dx.doi.org/10.1016/j.paid.2014.09.048

Zhou, Z.E., Yan, Y., Che, X.X., \& Meier, L.L. (2015). Effect of workplace incivility on end-ofwork negative affect: Examining individual and organizational moderators in a daily diary study. Journal of Occupational Health Psychology, 20, 117-130. http://dx.doi.org/10.1037/a0038167 


\section{Table 1.}

Descriptive Statistics

\begin{tabular}{|c|c|c|c|c|c|c|c|c|c|}
\hline Variable & Mean & S.D & 1 & 2 & 3 & 4 & 5 & 6 & 7 \\
\hline 1. Experienced Incivility & 1.96 & 0.95 & $(.95)$ & & & & & & \\
\hline 2. Agreeableness & 3.69 & 0.70 & $-.10 *$ & $(.71)$ & & & & & \\
\hline 3. Conscientiousness & 3.84 & 0.69 & $-.26 * *$ & $.36^{* *}$ & $(.66)$ & & & & \\
\hline 4. Extraversion & 2.96 & 0.17 & -.05 & $.33 * *$ & $.14^{* *}$ & $(.73)$ & & & \\
\hline 5. Neuroticism & 2.68 & 0.77 & $.34 * *$ & $-.11 *$ & $-.33 * *$ & $-.17 * *$ & $(.67)$ & & \\
\hline 6. Emotional Exhaustion & 2.03 & 0.93 & $.43 * *$ & $-.24 * *$ & $-.28 * *$ & $-.17 * *$ & $.28 * *$ & $(.94)$ & \\
\hline 7. Perpetrated Incivility & 1.68 & 0.79 & $.54 * *$ & $-.15^{*}$ & $-.33 * *$ & .02 & $.25^{* *}$ & $.65^{* *}$ & $(.95)$ \\
\hline
\end{tabular}

Notes: Coefficient alpha is displayed in parentheses on the diagonal. $* \mathrm{p}<.05 * * \mathrm{p}<.01$. 
Table 2.

Moderated Hierarchical Regression Analysis Predicting Psychological Strains

\begin{tabular}{|c|c|c|c|c|c|c|}
\hline & & \multicolumn{2}{|c|}{ Emotional Exhaustion } & \multicolumn{3}{|c|}{ Perpetrated Incivility } \\
\hline Hours & $\begin{array}{l}\text { Step } 1 \\
-.09\end{array}$ & $\begin{array}{l}\text { Step } 2 \\
-.08\end{array}$ & $\begin{array}{l}\text { Step } 3 \\
-.09\end{array}$ & $\begin{array}{l}\text { Step } 1 \\
.05\end{array}$ & $\begin{array}{l}\text { Step } 2 \\
.06\end{array}$ & $\begin{array}{l}\text { Step } 3 \\
.05\end{array}$ \\
\hline Ethnicity & .07 & .04 & .01 & -.04 & -.08 & $-.11 *$ \\
\hline Gender & -.02 & .05 & .03 & -.07 & -.003 & -.03 \\
\hline Incivility & & $.38 * *$ & $.39 * *$ & & $.49 * *$ & $.48^{* *}$ \\
\hline Agreeableness (A) & & -.13 & -.12 & & -.05 & -.03 \\
\hline Conscientiousness (C) & & -.03 & -.003 & & -.11 & -.08 \\
\hline Extraversion (E) & & $-.12^{*}$ & -.12 & & .07 & .07 \\
\hline Neuroticism (N) & & .07 & .07 & & .05 & .08 \\
\hline Incivility x A & & & $.17 *$ & & & $.14^{*}$ \\
\hline Incivility x C & & & $-.24 * *$ & & & $-.31 * *$ \\
\hline Incivility x E & & & -.04 & & & -.01 \\
\hline Incivility $\mathrm{x} N$ & & & -.10 & & & -.09 \\
\hline Total $\mathrm{R}^{2}$ & .01 & $.25 * *$ & $.29 * *$ & .01 & $.34 * *$ & $.40 * *$ \\
\hline$\Delta \mathrm{R}^{2}$ & .01 & $.24 * *$ & $.04^{* *}$ & .01 & $.33^{* *}$ & $.06^{* *}$ \\
\hline
\end{tabular}

Note: Standardized values are shown. Gender: (1= Male and 2=Female). Ethnicity: $(1=$ Black, African American; 2 = American Indian, Eskimo; 3 = White, Caucasian; $4=$ Asian $/$ Pacific Islander; 5 = Hispanic/Latino; $6=$ Other $) ; * \mathrm{p}<.01 ; * \mathrm{p}<.05$ 


\section{Figure 1.}

The interactive effect of incivility and agreeableness on emotional exhaustion.

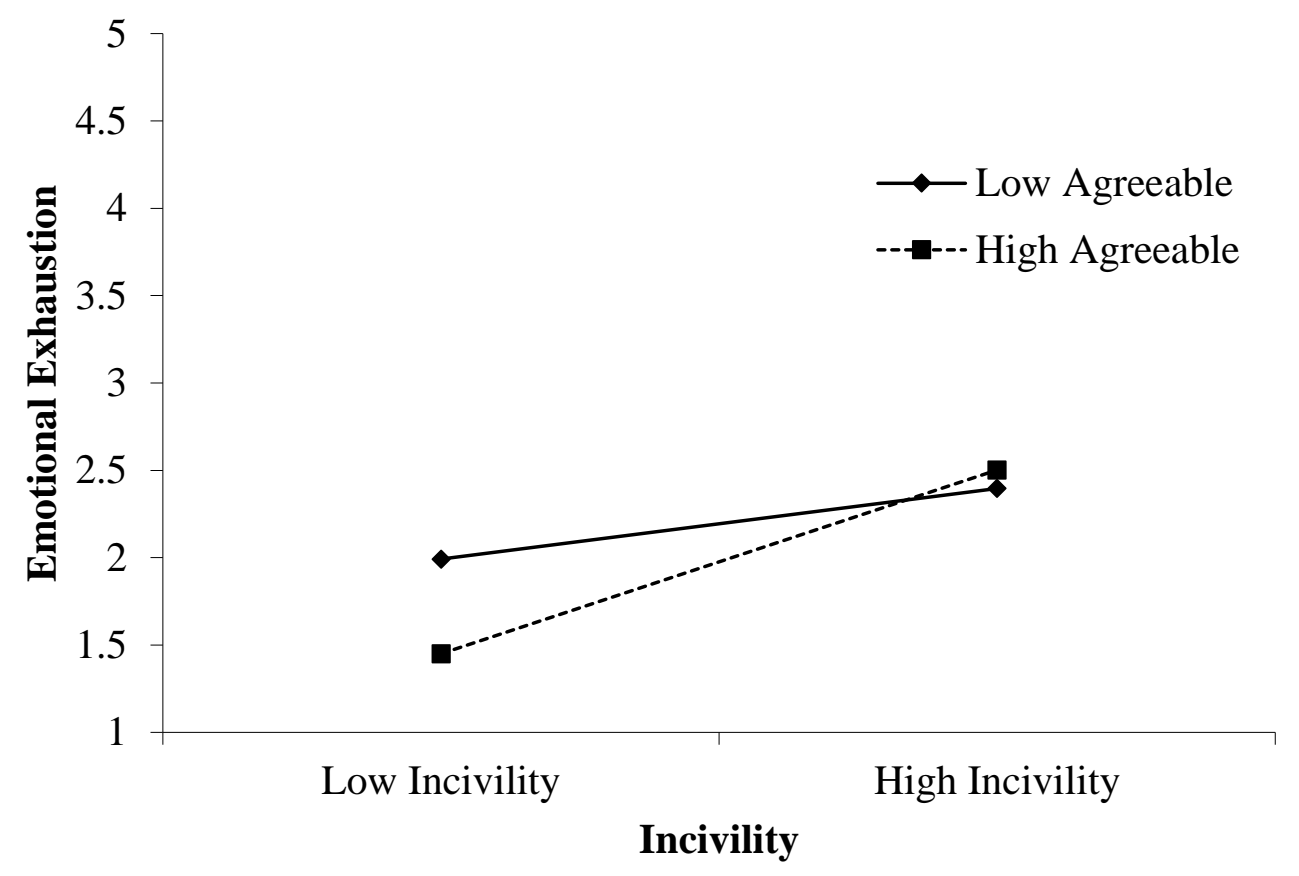




\section{Figure 2 .}

The interactive effect of incivility and agreeableness on perpetrated incivility.

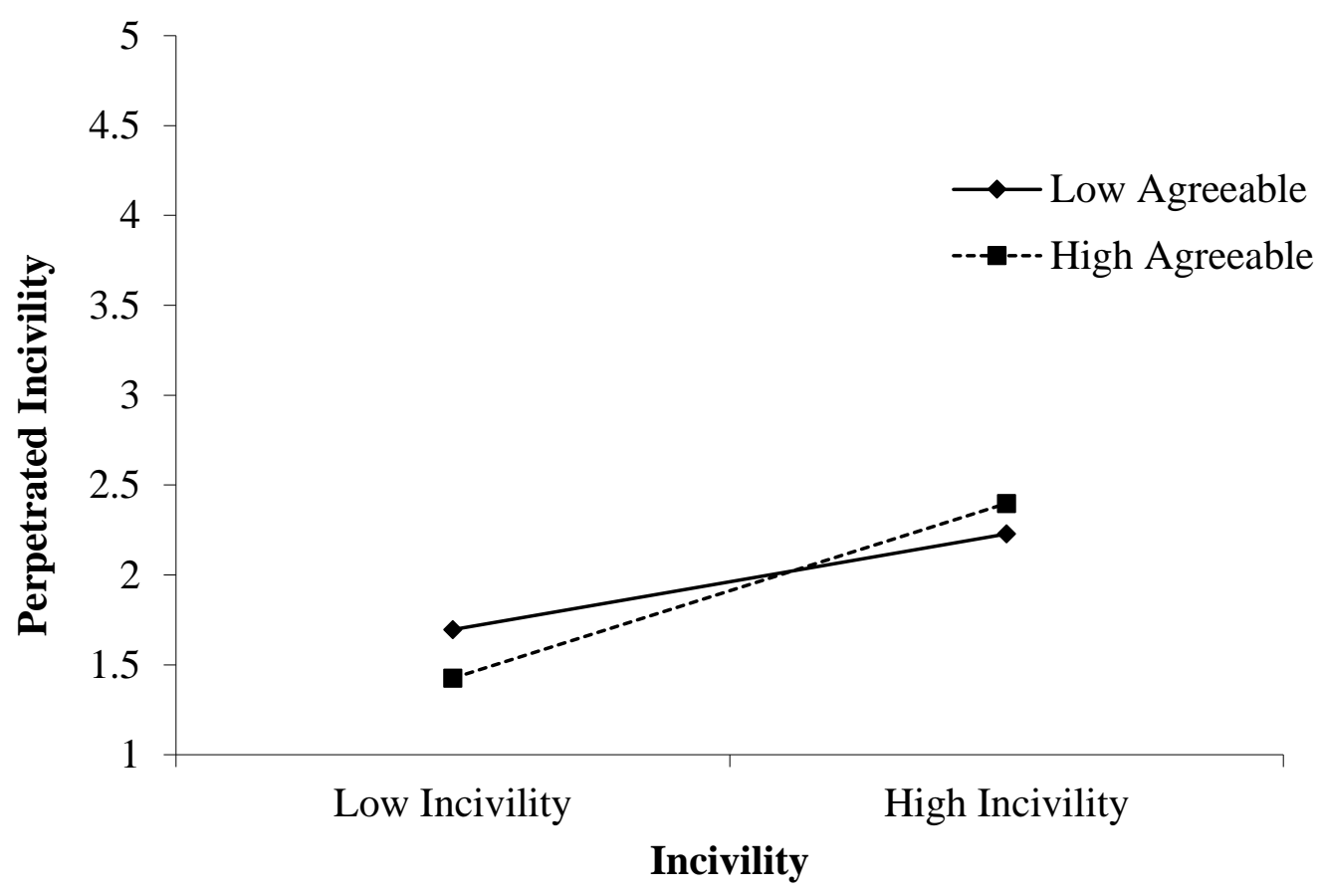




\section{Figure 3.}

The interactive effect of incivility and conscientiousness on emotional exhaustion.

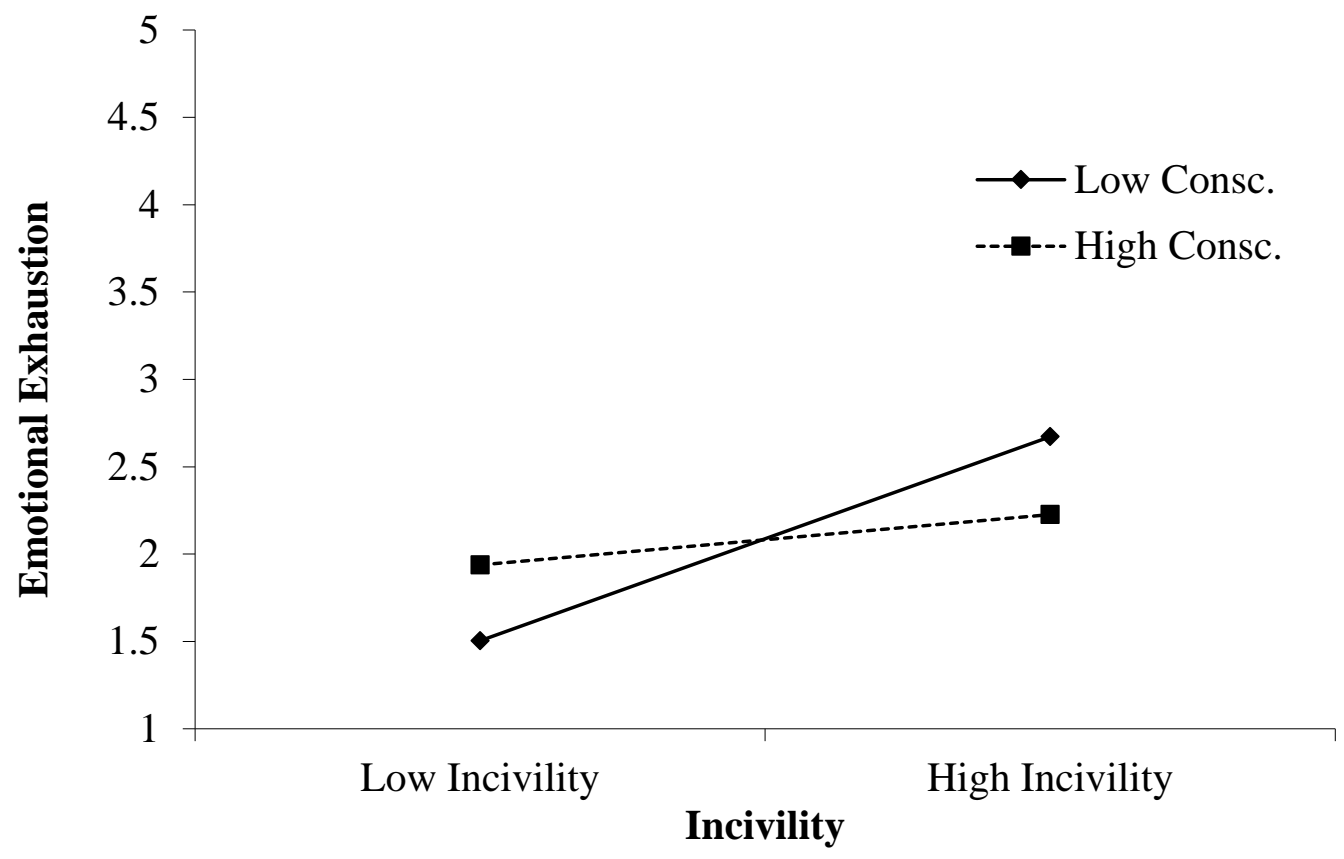




\section{Figure 4.}

The interactive effect of incivility and conscientiousness on perpetrated incivility.

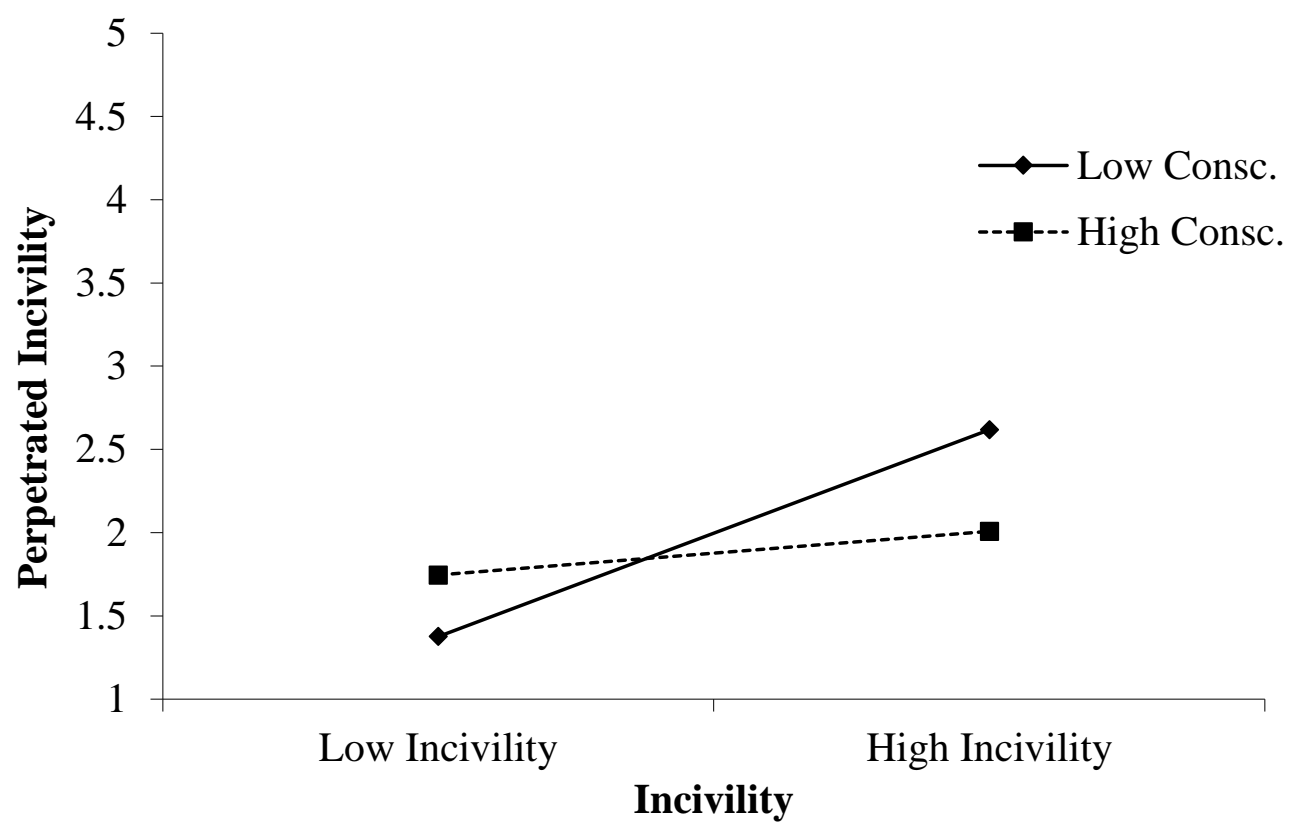

